\title{
A utilização dos recursos EAD como apoio ao ensino presencial na educação básica
}

Washington Romão dos Santos

Jonathan Toczek

Solange Sardi Gimenes

\begin{abstract}
Resumo
Este trabalho tem por finalidade discutir e apresentar as potencialidades que os ambientes virtuais proporcionam ao ensino presencial seja como ferramenta de apoio, seja como recurso de controle, interação e gerenciamento das atividades avaliativas. Esses recursos se tornam, a cada dia, mais eficazes devido à exigência de qualidade ditada pela ampliação dos cursos de ensino a distância. No entanto, os benefícios podem ser explorados também no ensino presencial com excelentes resultados, conforme pode ser observado no caso de estudo realizado no ensino médio integrado. Os estudantes têm um novo espaço para tirar dúvidas, participar de discussões e construir, seu próprio conhecimento, com o professor acompanhando a construção coletiva, norteando e envolvendo a turma.
\end{abstract}

Palavras-chave: AVA, Modelo Construtivista, Tecnologias Educacionais.

\begin{abstract}
This study aims to discuss and present the potential that virtual environments provide the classroom teaching, either as a support tool or as resource control, interaction and management of evaluation activities. These resources become increasingly more effective because of quality requirements dictated by the expansion of distance learning courses. However, the benefits can be exploited also in the classroom teaching, with excellent results, as can be seen in the case of study in high school built. Within this perspective, these resources can be included as a key planning education, expanding the horizons for a quality public education classroom, where technology assists in the process of teaching, providing interactive educational environments. Students have a new space to ask questions, participate in discussions and build more autonomous his own knowledge, the teacher accompanying the collective construction, performing whenever I need the necessary interventions, guiding and engaging class.
\end{abstract}

Keywords: VLE, Constructivist Model, Educational Technology. 


\section{Introdução}

As transformações que as novas tecnologias vêm promovendo na sociedade moderna nos levam a analisar e a refletir sobre a importância de conhecer e utilizar recursos tecnológicos como estratégia de ensino ou como ferramenta de estudo, buscando criar possibilidades educacionais ao relacionar conhecimentos que o professor leciona em sala de aula com conhecimentos tecnológicos que a sociedade disponibiliza, para ensinar e aprender de forma inovadora esses conteúdos. A sociedade do conhecimento exige pessoas mais dinâmicas e inovadoras, o que só é possível repensando a forma de agir no mundo, pensar sobre ele e encará-lo, portanto o professor deve estar aberto ao que as inovações tecnológicas podem oferecer de contribuição ao seu trabalho cotidiano.

Entre os maiores avanços da educação, especificamente no que tange aos aspectos tecnológicos, é possível destacar a evolução dos recursos empregados no ensino a distância (EAD), a popularização do computador e o uso da internet, os quais permitiram o advento de novas formas de ensinar e aprender. Evidência disso é o crescente aumento de cursos disponíveis a distância, que, se levados a sério pelas instituições de ensino e pelos alunos, não perdem em nada para o ensino presencial e, até pelo contrário, permitem formar alunos com elevada autonomia e independência. O Ambiente Virtual de Aprendizagem - AVA - disponibiliza, através de uma plataforma, material para leitura complementar, espaço de interação e resolução de dúvidas, chats, jogos, vídeos didáticos, entre outros recursos que podem ser usados conforme as necessidades de cada conteúdo, auxiliando o trabalho do professor. O interesse deste trabalho é divulgar o potencial dos recursos tecnológicos - utilizados principalmente no ensino a distância no apoio às atividades do professor no ensino presencial, ou seja, aliar as ferramentas virtuais de aprendizagem ao cotidiano de sala de aula tradicional. Para cumprir esse objetivo, os recursos dos Ambientes Virtuais de Aprendizagem foram aplicados em duas disciplinas de ensino técnico, cujos planos de ensino preveem o apoio de ferramentas de ensino a distância durante a realização das aulas. Os resultados foram analisados com uma abordagem qualitativa, de maneira a permitir não só comprovar os benefícios desses recursos como também fazer uma reflexão sobre como utilizálos de maneira adequada.

Antes de mais nada, é preciso reconhecer que a aliança entre os recursos virtuais facilitados pela internet e o ensino presencial já vem sendo promovida mesmo antes de os cursos utilizando a modalidade a distância serem reconhecidos pelo MEC. No entanto, foi com o advento das plataformas AVA, impulsionado pelas necessidades dos cursos EAD, que novas possibilidades educacionais tornaram-se possíveis. $O$ ensino presencial, sobretudo nas instituições particulares e universidades federais, acompanhou esses avanços, porém, em instituições públicas de ensino básico, praticamente nada relacionado a essas possibilidades educacionais diferenciadas pode ser encontrado. Assim, os estudos aqui apresentados oferecem resultados capazes de preencher essa lacuna, ajudando a disseminar o conceito e as possibilidades do ensino a distância desde o ensino 
básico. Trabalho similar pode ser encontrado também em Gimenes, Santos e Toczek (2012), integrando a matemática do ensino fundamental com a informática através dos Ambientes Virtuais de Aprendizagem.

\section{Os Ambientes Virtuais de Aprendizagem}

Os computadores passaram de gigantescas máquinas a itens acessíveis a todos em qualquer lugar no mundo e, juntamente com a internet, que surgiu com a proposta de democratizar a informação, alteraram a forma como vemos o mundo hoje. A escola deve estar atualizada com os novos meios e ferramentas para o ensino; o computador é hoje indispensável no dia a dia dos alunos e professores, bem como a internet, que tem se tornado um meio de interação revolucionário, permitindo que pessoas isoladas geograficamente possam se comunicar com o resto do mundo. Orlandi (2011, p. 17) sustenta a importância da informática ao dizer que: "A introdução do computador, no ambiente escolar, é hoje uma necessidade para o crescimento de uma pedagogia inovadora, assentada na capacidade de educadores propensos a didáticas renovadas". Moran (2002), por sua vez, diz que:

"A Internet está caminhando para ser audiovisual, para transmissão em tempo real de som e imagem (tecnologias streaming, que permitem ver o professor numa tela, acompanhar o resumo do que fala e fazer perguntas ou comentários). Cada vez será mais fácil fazer interações mais profundas entre TV e WEB [...]. Enquanto assiste a determinado programa, o telespectador começa a poder acessar simultaneamente às informações que achar interessantes sobre o programa, acessando o site da programadora na Internet ou outros bancos de dados."

Nesse contexto, entendendo que o computador e a internet devem ser usados com finalidade pedagógica e que a escola, na figura do professor, deve direcionar o conteúdo ministrado, sendo minuciosamente planejado, a fim de atender aos objetivos contidos no plano de ensino, soluções precisam ser desenvolvidas para que os recursos disponíveis sejam usados de forma a trazer os benefícios idealizados. No início do processo de informatização das escolas, a estranheza que o computador despertava acabou por não permitir o pleno uso dessa importante ferramenta, entretanto, com o passar dos anos, com a criação e aperfeiçoamento de sistemas, plataformas de ensino e programas educativos, os computadores puderam ser inseridos no cotidiano escolar de forma permanente.

A internet e suas ferramentas têm sido usadas para atender as expectativas de mudança que o mundo tem criado, pois ela transforma o processo de ensino-aprendizagem, uma vez que o aluno tem acesso às informações e autonomia na maneira de buscar o conteúdo que deseja e de utilizar racionalmente o tempo que possui. A transmissão do conhecimento acontece de forma 
bem diferente, não precisa ocorrer em um ambiente restrito, fechado, nem exige constante contato com o professor em sala de aula. Ela realiza-se em qualquer lugar, seja em casa, seja na biblioteca ou outro lugar que tenha um computador e acesso à rede mundial de computadores, ou seja, os espaços de aprendizagem se ampliaram com as possibilidades da internet, e o desenvolvimento dos Ambientes Virtuais de Aprendizagem corroboram essa nova abordagem.

Os Ambientes Virtuais de Aprendizagem são sistemas completos que dispõem de recursos criativos como fóruns, wikis, videoconferências, chats, além de oferecerem a possibilidade de se resolver atividades on-line e, dependendo do conteúdo a ser ministrado e do grau de complexidade exigido, ainda há outros recursos. Uma característica interessante dos AVAs é a inserção de novos recursos à medida que a internet evolui, assim as inovações tecnológicas desenvolvidas são agregadas à plataforma. Segundo Pereira, Schmitt e Dias (2007, p. 4-5):

"Em termos conceituais, os AVAs consistem em mídias que utilizam o ciberespaço para veicular conteúdo e permitir interação entre os atores do processo educativo. Porém, a qualidade do processo educativo depende do envolvimento do aprendiz, da proposta pedagógica, dos materiais veiculados, da estrutura e qualidade de professores, tutores, monitores e equipe técnica, assim como das ferramentas e recursos tecnológicos utilizados no ambiente."

Os AVAs agregam interfaces que permitem a produção de conteúdos e formas variadas de comunicação, além disso, também possibilitam o gerenciamento de banco de dados e o controle total das informações que circulam no ambiente e que, por ele, foram geradas, aumentando a eficiência e o controle do conteúdo e dos resultados. Essas características têm permitido que pessoas geograficamente espalhadas pelo mundo tenham a possibilidade de interagir em locais e tempos diferentes, situação impensada até pouco tempo atrás. O Ambiente Virtual de Aprendizagem tem sido um instrumento largamente utilizado no ensino a distância, que oferece possibilidades interessantes e, sendo usado no ensino presencial de diversas formas, pode representar uma alternativa para dinamizar as aulas e tornar o ensino mais agradável e interessante para o aluno, além de inserir a tecnologia diretamente no contexto escolar. A utilização dos recursos disponíveis nos AVAs requer a existência de uma infraestrutura adequada atrelada a uma proposta pedagógica eficiente, fatores imprescindíveis na promoção de melhorias significativas do ensino-aprendizagem e de ganhos qualitativos para os alunos no que tange a aprendizagem. 


\section{Possibilidades de aplicação dos recursos EAD no ensino presencial}

Normalmente é durante os estudos individuais ou coletivos com a resolução dos exercícios que o aluno terá dúvidas, e isso, muitas vezes, acontece fora do ambiente escolar. Em casos como esse, com os recursos de ensino a distância, o aluno tem o potencial de trazer consigo o ambiente escolar, permitindo que as dúvidas sejam encaminhadas on-line, compartilhando-as com os outros colegas, gerando integração e a construção ativa do conhecimento de forma coletiva. Para Piaget (1973 apud LA TAILLE; OLIVEIRA; DANTAS, 1992) "a inteligência humana somente se desenvolve no indivíduo em função de interações sociais que são, em geral, demasiadamente negligenciadas". Essa afirmação reforça a importância de favorecer o envolvimento do aluno no processo de construção do aprendizado.

A construção do conhecimento pode ser potencializada com o uso dos recursos virtuais, pois eles permitem a interação entre os estudantes; o professor, nesse contexto, tem a função de facilitador que estimula a curiosidade dos alunos, a pesquisa e o senso crítico, abrindo caminho para o questionamento, para a exploração de novas possibilidades e para a construção da autonomia. A interatividade e a organização da sala virtual são componentes que colaboram para que o estudante possa prosseguir nos seus estudos com mais segurança, através das informações fornecidas pelo próprio sistema, que tendem a ser didáticas.

O Ambiente Virtual de Aprendizagem oferece possibilidades de organização para o ensino presencial, com ferramentas como: fórum, bibliotecas, tira-dúvidas, bibliografias, arquivos para download, mural de avisos, bate-papo, recepção e envio de materiais e gerenciadores de tarefas. Entre essas ferramentas, o fórum é apontado como veículo motivador para a troca de experiências, tornando o ambiente colaborativo. Com o fórum, o professor pode propor um tema, provocando uma discussão que será realizada de forma assíncrona, a postagem é vista por todos os colegas, e o aluno tem a flexibilidade do horário para utilizar o ambiente. Desse modo, o aluno aproveita melhor seu tempo, tem mais liberdade e, não compromete a interatividade do grupo, pois o diálogo é mantido. Segundo Kensky (2010 apud ORLANDI, 2011, p. 52):

"Esses espaços virtuais de aprendizagem oferecem condições para a interação (síncrona e assíncrona) permanente entre os seus usuários. A hipertextualidade facilita a propagação de atitudes de cooperação entre os seus participantes, para fins de aprendizagem. A conectividade garante o acesso rápido à informação e à comunicação interpessoal, em qualquer tempo e lugar, sustentando o desenvolvimento de projetos em colaboração e a coordenação das atividades. Essas três características - interatividade, hipertextualidade e 
conectividade - já garantem o diferencial dos ambientes virtuais para a aprendizagem individual e grupal."

Existe uma interação entre o aprendiz e os recursos tecnológicos, pois, com o computador, o aluno sente prazer em utilizar as ferramentas sem ter que ser totalmente conduzido pelo professor, desenvolve a autonomia, além de usufruir da possibilidade de integração entre diversas disciplinas do ensino básico (GIMENES; SANTOS; TOCZEK, 2012). $O$ aluno deverá, por exemplo, estar sempre atento à escrita, uma vez que toda contribuição estará registrada.

O planejamento e a montagem da sala virtual no ensino presencial deverão considerar algumas diferenças. Normalmente, quando se planeja uma disciplina a distância, o professor faz um dimensionamento do tempo necessário para trabalhar cada um dos conteúdos, que são, em geral, organizados em semanas. Por outro lado, no ensino presencial, esse dimensionamento é desnecessário; o professor deve organizar sua sala virtual por conteúdos, em vez de semanas. 0 tempo que o professor levará para ministrar cada um dos conteúdos depende da turma e da profundidade da abordagem, entre outros fatores. A noção de tempo deve se aproximar de maneira similar ao ritmo da sala de aula presencial. A figura 1, a seguir, mostra um recorte de como a sala virtual pode ser organizada. Repare que cada conteúdo, este bem definido, é apresentado juntamente com o material e atividades previstas. O professor deve dimensionar a sala, tomando cuidado com o número de tópicos, para evitar deixá-la muito grande e, consequentemente, de difícil gerenciamento. A melhor forma de montar uma sala virtual vai depender do tipo de conteúdo a ser ministrado, da boa junção entre as funcionalidades disponíveis e do estilo do professor, criando um ambiente organizado, que tenha clareza e que estimule o aprendizado.

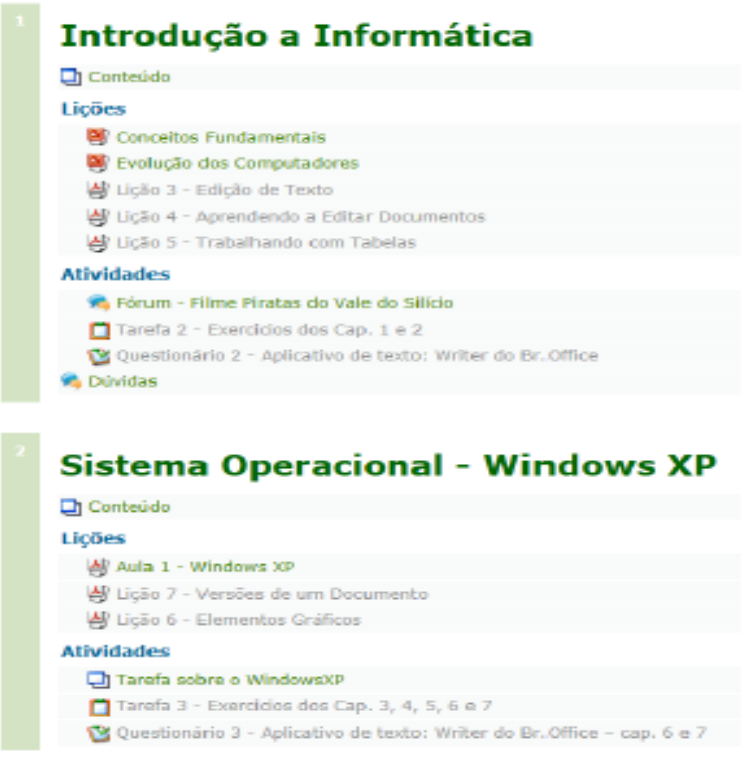

Figura 1 - Recorte da sala virtual aplicada como caso de estudo 
As vantagens de aliar os recursos tecnológicos virtuais com o ensino presencial são enormes e alinham-se à constante pressão que o professor sofre, por parte das secretarias de educação e do próprio governo, para aumentar o tempo de permanência em sala de aula, expandir a quantidade de conteúdos obrigatórios no currículo da educação básica e aprofundar mais os conteúdos ministrados. A principal vantagem observada é a eficiência do trabalho educacional, substituindo o método transmissivo e propondo-se ao diálogo construtivo:

"Deixa de ser um mero transmissor de saberes. Deverá converte-se em formulador de problemas, provocador de interrogações, coordenador de equipes de Trabalho, sistematizador de experiências e memória viva de uma educação que, em lugar de aferrar-se a passado (transmissão), valoriza e possibilita o diálogo entre culturas e gerações (MARTíN-BARBERO, 1998, p. 23 apud SILVA, 2002, p. 70)."

O professor pode discutir com os alunos em sala de aula, ouvir sugestões, propor atividades mais relacionadas com a realidade dos alunos e, com isso, desenvolver formas mais apropriadas de construir conhecimento. O educador poderá ser um mediador no ensino presencial, estimulando a autonomia e fornecendo um feedback dos comentários e atividades desenvolvidas. Contudo, é necessário incentivo e valorização desse método de ensino.

\section{Metodologia e métodos}

Este trabalho aplica a metodologia de análise do uso dos recursos virtuais de aprendizagem em duas turmas, que utilizaram durante um semestre uma plataforma de aprendizagem, o Moodle, através da qual o aprendizado da informática básica passou a processar-se em ambiente virtual como complemento à componente presencial. Nessa plataforma, foi construída uma sala de aula virtual ou Ambiente Virtual de Aprendizagem, onde os alunos puderam estudar e interagir utilizando uma série de ferramentas, entre as quais os fóruns de discussão, os questionários on-line, vídeos explicativos e tarefas on-line e off-line.

As turmas eram compostas por estudantes com experiência de utilização de redes sociais e da plataforma Moodle em contexto de aprendizagem disciplinar. A pesquisa foi realizada entre os meses de agosto e dezembro de 2011. Além da observação, foi aplicado um questionário semiestruturado aos alunos, contendo perguntas sobre a utilização da plataforma e sobre a opinião deles quanto aos benefícios da sala virtual nas aulas presenciais. A sala virtual funcionou não só como espaço destinado à troca de ideias, acesso ao material da disciplina e do pensamento crítico mas também como um local de construção da autonomia onde os conhecimentos adquiridos foram complementados e sintetizados através da junção 
das atividades realizadas nas aulas presenciais com outras desenvolvidas no ambiente virtual.

\section{Resultados alcançados}

Foi feita uma pesquisa com abordagem qualitativa para levantar a opinião dos alunos e entender como eles enxergam os Ambientes Virtuais de Aprendizagem, a fim de avaliar o potencial educacional desses recursos tecnológicos e as vantagens de sua inserção no ensino presencial. A utilização dos AVAs com mais regularidade demonstra que eles propiciam vantagens no dia a dia do aluno, que tem uma visão positiva dessa tecnologia e entende que ela é uma realidade e deve estar cada vez mais presente no ambiente escolar.

Entre as opiniões e sugestões levantadas, existe um consenso de que as aulas melhoram quando o professor utiliza os recursos das salas virtuais para dinamizá-las. Os que usaram essa tecnologia com maior frequência consideram-na uma possibilidade interessante e promissora, útil para desenvolver conteúdos e otimizar o tempo e logo compreendem que ela atua como auxiliar no processo de ensino-aprendizagem, dando suporte ao trabalho do professor e ajudando o aluno a aprender de forma mais fácil.

Com as informações coletadas pela pesquisa, os professores puderam perceber a necessidade de promover algumas ações de interação. Isso pode ser constatado pelo gráfico da Figura 2, que quantifica os recursos mais utilizados pelos alunos.

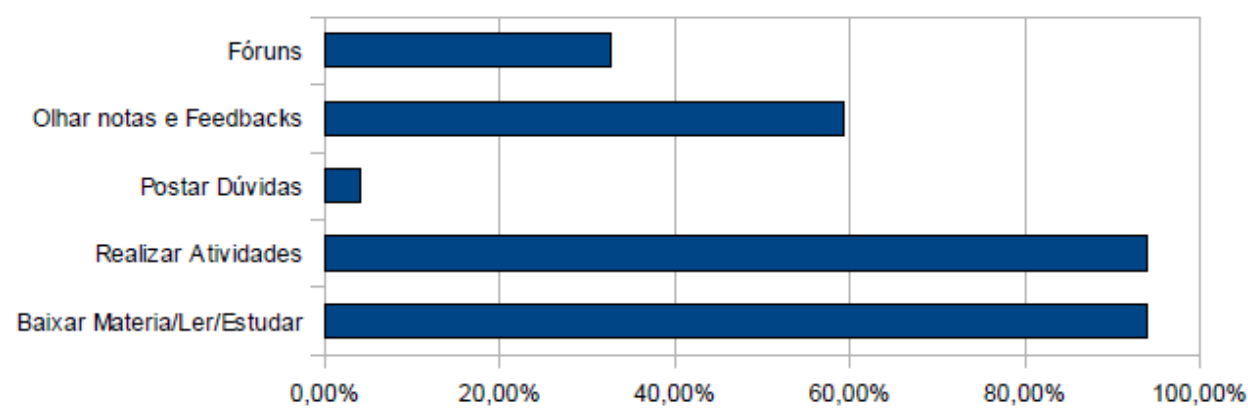

Figura 2 - Percentual de utilização dos recursos

Através do gráfico da Figura 3, percebe-se que existiu um trabalho de motivação para que os alunos efetivamente utilizassem o ambiente. Os alunos sentiam necessidade de acessar o ambiente para a leitura dos materiais de estudos e para a realização de atividades avaliativas, porém, os professores reconhecem que poderiam incentivar mais as discussões nos fóruns e o uso da ferramenta como apoio para esclarecimentos de dúvidas. 


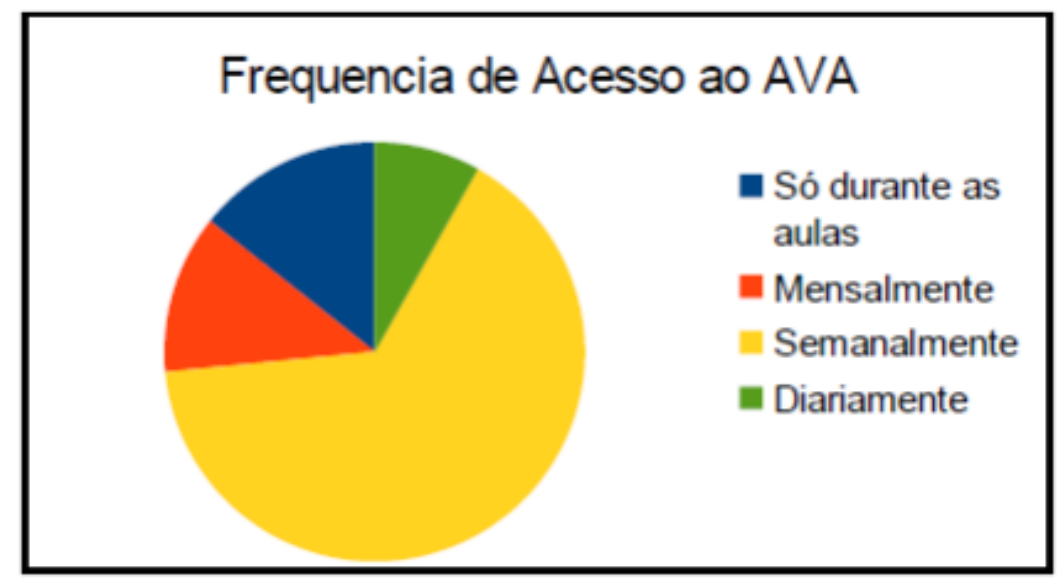

Figura 3 - Frequência que os alunos do curso acessam o AVA

A Tabela 2 corrobora esse dado, visto que a avaliação dos alunos em relação à interação do professor, apesar de não ser majoritariamente negativa, contrasta com a dos demais itens, aos quais acima de 70\% dos alunos atribuíram o valor "bom" ou "ótimo", com destaque para as atividades e os recursos didáticos, considerados "bom" ou "ótimo" por mais de $80 \%$ dos entrevistados. Alguns alunos relataram que a utilização dos recursos deixa as aulas mais atraentes e que todos os professores deveriam usar esses artifícios para estimular o estudo.

As informações constantes nas tabelas fornecem uma indicação de como os Ambientes Virtuais de Aprendizagem foram trabalhados e de quais medidas podem ser tomadas para melhorar a avaliação dos alunos quanto a alguns recursos, pois, na medida em que a plataforma é vista como útil nas aulas ou no momento que os alunos a acessam, ela será melhor e mais usada tanto por eles quanto pelo professor.

Tabela 1 - Opinião dos alunos em relação ao potencial para o ensino do AVA

\begin{tabular}{|l|l|l|l|}
\hline & Não & Mais ou & Gostei \\
\hline Fórum & 10,00 & $70,00 \%$ & $20,00 \%$ \\
\hline Escolha seu grupo & $9,76 \%$ & $48,78 \%$ & $41,46 \%$ \\
\hline Envio de Atividades & $0,00 \%$ & $23,26 \%$ & $76,74 \%$ \\
\hline Visualização do material didático & $0,00 \%$ & $23,81 \%$ & $76,19 \%$ \\
\hline Visualização das notas & 14,29 & $38,10 \%$ & $47,62 \%$ \\
\hline Questionários & 15,79 & $60,53 \%$ & $23,68 \%$ \\
\hline Mensagens & 13,95 & $46,51 \%$ & $39,53 \%$ \\
\hline
\end{tabular}


Tabela 2 - Opinião dos alunos em relação aos recursos utilizados

\begin{tabular}{|l|l|l|l|l|}
\hline & Ruim & Regular & Bom & Ótimo \\
\hline $\begin{array}{l}\text { Em relação às atividades práticas e avaliativas } \\
\text { propiciadas }\end{array}$ & $0,00 \%$ & $14,29 \%$ & $44,90 \%$ & $40,82 \%$ \\
\hline Em relação ao conteúdo didático propiciado & $2,04 \%$ & $18,37 \%$ & $36,73 \%$ & $42,86 \%$ \\
\hline $\begin{array}{l}\text { Em relação ao Feedback das atividades } \\
\text { propiciado }\end{array}$ & $6,12 \%$ & $22,45 \%$ & $48,98 \%$ & $22,45 \%$ \\
\hline Em relação à interação do professor & $6,12 \%$ & $32,65 \%$ & $42,86 \%$ & $18,37 \%$ \\
\hline
\end{tabular}

É importante considerar que os dados foram levantados com base na aplicação dos recursos em duas disciplinas, em um primeiro protótipo, de tal modo que, diante dos resultados apresentados, é natural a tendência do professor de inserir melhorias nas suas salas virtuais. Os fóruns, por exemplo, não foram tão estimulados quanto poderiam ser, e, talvez por isso, os alunos não tenham visualizado seu potencial. O mesmo aconteceu com o questionário, que, durante o período da pesquisa, só foi utilizado uma vez. Por outro lado, é fácil perceber um resultado excelente para os recursos mais utilizados.

\section{Conclusão}

As diversas possibilidades que a inserção dos recursos virtuais que utilizam os AVAs traz ao ensino é uma realidade que deve ser abraçada pelas instituições de ensino, não como uma forma de reduzir o contingente de professores para um número cada vez maior de alunos, e sim como ferramenta de apoio aliada ao ensino presencial, com a criação de novos instrumentos de estímulo, possibilitando a construção de um conhecimento cada vez mais sólido.

Essa é uma necessidade emergente que se alinha ao perfil cada vez mais interativo dos adolescentes e jovens atuais, capaz de fornecer instrumentos modernos e atraentes aos alunos do novo milênio, "os conectados". O fato de haver um local onde os alunos podem interagir entre si e com o professor, tirando dúvidas e favorecendo a própria construção do conhecimento, é algo que poderá transformar de forma significativa a educação.

O papel do professor como mediador do processo de inserção de novas tecnologias no ensino é imprescindível: ele deve entender a tecnologia e a utilidade dela e fazer o uso racional de seus recursos, disponibilizando e direcionando as informações pertinentes à disciplina ou ao conteúdo que vai ministrar. As contribuições da tecnologia só serão úteis com a devida 
racionalização e um olhar crítico sobre sua utilidade em dado momento. Moran, Masetto e Behrens (2000, p. 23) dizem que:

"Um dos grandes desafios para o educador é ajudar a tornar a informação significativa, a escolher as informações verdadeiramente importantes entre tantas possibilidades, a compreendê-las de forma cada vez mais abrangente $e$ profunda e a torná-las parte do nosso referencial."

Este trabalho demonstra isso através de resultados sólidos, com dados compilados de uma amostragem composta de 49 dos 70 alunos que cursaram as disciplinas. A informação resultante desses dados ajuda a demonstrar o potencial dos recursos de EAD e do uso dos Ambientes Virtuais de Aprendizagem como uma alternativa para dinamizar as aulas e tornar o ensino presencial mais agradável e interessante. No entanto, é importante reconhecer que a utilização dos recursos disponíveis nos AVAs requer a existência de uma infraestrutura adequada, atrelada a uma proposta pedagógica eficiente, fatores imprescindíveis na promoção de melhorias significativas do ensino-aprendizagem. Além disso, para alcançarmos todo o potencial desta crescente realidade, é necessária uma mudança gradativa da educação pública brasileira, de maneira que a formação, atendimento e acompanhamento dos alunos através dos recursos de EAD sejam incentivados da mesma forma e na mesma medida que o são durante o cumprimento da carga horária em sala de aula, permitindo ao professor tirar dúvidas, corrigir atividades ou interagir virtualmente com os alunos.

\section{Referências Bibliográficas}

BELLONI, Maria Luiza. Educação a distância. 3. ed. Campinas, São Paulo: Autores Associados, 2003.

BOUCHARD, Paul. Autonomia e distância transacional na formação a distância. In: ALAVA, Seraphin (Org.). Ciberespaço e formações abertas. Porto Alegre: Artmed, 2000.

GIMENES, Solange Sardi; SANTOS, Washington Romão; TOCZEK, Jonathan. Possíveis interfaces entre matemática e informática em ambientes virtuais no espaço escolar. In: IX ENCONTRO CAPIXABA DE EDUCAÇÃO MATEMÁTICA, 2012, Vitória. Pôster.

LA TAILLE, Yves de; OLIVEIRA, Marta Kohl de; DANTAS, Heloysa. Piaget, Vygotsky, Wallon: Teorias psicogenéticas em discussão. São Paulo: Summus, 1992.

MILHOLLAN, Frank; FORISHA, Bill E. Skinner x Rogers. 3. ed. São Paulo: Summus, 1978. 
MORAN, José Manuel. 0 que é educação à distância. 2002. Disponível em:

$<$ http://www.eca.usp.br/prof/moran/site/textos/educacao_online/dist.pdf $>$. Acesso em 30 jan. 2012.

MORAN, José Manuel; MASETTO, Marcos; BEHRENS, Marilda. Novas tecnologias e mediação pedagógica. São Paulo: Papirus, 2000.

ORLANDI, José Geraldo. Tecnologias integradas à educação. Cachoeiro de Itapemirim: Ifes, 2011. PEREIRA, Alice Theresinha Cybis; SCHMITT, Valdenise; DIAS, Maria Regina Álvares C. Ambientes Virtuais de Aprendizagem. 2007. Disponível em:

<http://www.academia.edu/1007458/Ambientes_Virtuais_de_Aprendizagem>. Acesso em: 8 fev. 2012.

RIBEIRO, José Geraldo Gomes da Cruz. A psicologia fenomenológica existencial: uma nova perspectiva de relação. In: Kullok, Maisa Gomes Brandão (Org.). Relação professor-aluno: contribuições à prática pedagógica. Maceió: EDUFAL, 2002. p. 37-50. 1978. Disponível em: $<$ http://books.google.com.br/books?id=_1bZ2afrJn4C\&pg=PA39\&hl=ptBR\&source=gbs_toc_r\&cad=4\#v=onepage\&q\&f=false>. Acesso em: 10 mar. 2012.

SANTOS. Edméa Oliveira. Ambientes virtuais de aprendizagem: por autorias livres, plurais e gratuitas. Revista FAEEBA, Salvador, v. 11, n. 18, p. 425-435, jul./dez. 2002. Disponível em: <http://www.uneb.br/revistadafaeeba/files/2011/05/numero18.pdf>. Acesso em: 30 jan. 2012.

Washington Romão dos Santos: Licenciado em Informática pelo Instituto Federal do Espírito Santo. Washington romao@hotmail.com

Jonathan Toczek: Professor do Instituto Federal do Espírito Santo - Campus Guarapari. J.toczek@hotmail.com

Solange Sardi Gimenes: Professora da rede estadual do Espírito Santo. solange.sardi@gmail.com 